\title{
4
}

\section{Sonographic Changes in Hypoxic-Ischaemic Encephalopathy}

\author{
Pilvi Ilves \\ University of Tartu \\ Estonia
}

\section{Introduction}

Hypoxic-ischaemic encephalopathy (HIE) in a full-term infant is a clinically defined syndrome of the disturbed neurologic function in the earliest days after birth in infancy, manifested by difficulty with initiating and maintaining respiration, the depression of the muscle tone and reflexes, the subnormal level of consciousness and often seizures (Nelson \& Leviton, 1991). HIE is the term used to describe the resultant condition due to a deficit in the oxygen supply to the brain. The neonatal brain can have a lack of oxygen through two major pathogenetic mechanisms, hypoxemia, which is a diminished amount of oxygen in the blood supply, and ischemia, which is a diminished amount of blood perfusing the brain. During the perinatal period hypoxemia or ischemia or both occur as a result of asphyxia, an impairement in the exchange of respiratory gases, oxygen and carbon dioxide. The duration and severity of HIE depend of the severity of asphyxia. Neonatal asphyxial encephalopathy occurs in 1-2 per 1000 births in the high income countries (Marlow \& Budge, 2005; Pierrat et al., 2005; Barkovich, 2005), in low-income countries, the incidence is much higher (Ellis et al., 2000; Black et al., 2010).

Despite major advances in obstetric and neonatal care, and the introduction of therapeutic hypothermia, HIE is still a devastating occurrence that results in death or disability in $47 \%$ of infants with moderate or severe HIE (Edwards et al., 2010). As survivours of severe HIE have profound long-term neurologic disability like cerebral palsy, mental retardation and epilepsy (Finer et al., 1992; Perlman, 2006) and a large majority of infants with moderate HIE have cognitive problems (Lindström et al., 2008), sequelae of hypoxic-ischaemic brain injury require significant resources (Lindström et al., 2008).

The principal mechanism of pathogenesis underlying most of the neuropathology attributed to intrapartum hypoxia-ischemia is impaired cerebral blood flow, which occurs most likely because of interruption in placental blood flow and gas exchange (Perlman, 2006).

However, the development of brain injury after hypoxia-ischemia is an evolving process which is initiated during the hypoxic-ischemic insult but extend into the reperfusion period during recovery (Fellman \& Raivio, 1997; Perlman, 2006). The brain damage, following hypoxic-ischemic insults, develops after a delay, being preceeded by the symptom-free interval or even the temporary improvement of the clinical picture immediately after insult (van Bel et al., 1998). The time before the full development of brain damage represents a 
window of opportunity for therapeutic interventions (Robertson \& Edwards, 1998). It is therefore essential to assess the severity of asphyxia in the newborn infant as soon as possible after birth or during the first hours after asphyxia to provide adequate care and treatment before the final damage develops. As the duration and severity of asphyxia may be difficult to estimate and the compensatory capacity of the foetus and newborn is unknown, it may be difficult to predict the severity of organ damage immediately after birth based on the clinical findings only.

The treatment of HIE consists largely of supportive care, which does little to reduce the ongoing injury that develops in the hours immediately following the hypoxic-ischemic insult. Providing standard intensive care support, correcting metabolic acidosis, close monitoring of the fluid status, and seizure control are the main elements of treatment in patients with HIE (Stola \& Perlman, 2008). In recent years, randomised trials of hypothermia (reducing the core temperature by $3.5{ }^{\circ} \mathrm{C}$ for $72 \mathrm{~h}$ ) have convincingly shown a neuroprotective effect (Edwards et al., 2010) and increase intact survival after birth asphyxia (Hagmann et al., 2011). Cooling is recommended after severe birth asphyxia by both the UK NICE (http://www.nice.org.uk/) and the International Consensus of Cardiopulmonary Resuscitation (ILCOR) guidelines (2010) (Perlman et al., 2010). Over the last two decades, promising new neuroprotective strategies designed to limit the extent of brain injury caused by hypoxia-ischemia have been under investigation (Robertson \& Edwards, 1998; Shadid et al., 1998; Thoresen \& Whitelaw, 2000; van Bel et al., 1998). Many of these promising treatment strategies, including hypothermia and the administration of antagonist against excitatory amino acids or free radicals, have a limited window of effectiveness (in some cases as little as 6 hours), making early detection of injury critically important (Shadid et al., 1998; Thoresen \& Whitelaw, 2000; van Bel et al., 1998). Neuroimaging with ultrasonography (US), computed tomography (CT), and magnetic resonance imaging (MRI) have become increasingly valuable in the pre-treatment work-up of patients with HIE as they can provide information on the severity and extent of injury (Huang \& Castillo, 2008).

US is a simple radiological method easily applicable in critically ill children (Ilves et al., 2009a, 2009b). Cranial US is a useful tool to early detect developmental abnormalities and exclude other causes of encephalopathy than hypoxia-ischemia (Epelman et al., 2010; Lowe \& Bailey, 2011a, 2009b). Doppler US is a non-invasive method, which allows repeated and safe assessment of hemodynamics in neonatal units (Ilves et al., 2008, 2009a, 2009b). Several studies have demonstrated that the pulsed Doppler technique can be used to examine the pattern of blood flow velocity (BFV) in the major vessels of the brain (Ehehalt et al., 2005) as well as visceral organs (Weir et al., 1995) in neonates with good reproducibility. The BFV findings have clinical relevance in interpreting the cardiovascular adaptation of distressed newborn infants with a decompensation of circulatory responses and the possible development of multiorgan failure including brain damage (Ilves et al., 2009b).

Although MRI is the reference standard for infant brain imaging (Barkovich, 1992, 2005; Epelman et al., 2010; Martin et al., 1995; Rutherford et al., 1994, 1996), it is expensive, often requires sedation and transportation of the neonate, and may not be possible to perform on critically ill patients (Lowe \& Bailey, 2011a). With the improvement in sonographic equipment, the visualization of a variety of pathology and anatomic variants has become more feasible. Recent studies, using modern ultrasound equipment, have shown that cranial US is diagnostically accurate compared with MRI and useful to determine initial clinical 
management (Epelman et al., 2010; Lowe \& Bailey, 2011a). In experienced hands, US is an excellent tool to detect the most frequently occurring brain abnormalities in the preterm and full-term neonates, to study the evolution of lesions, and to follow brain maturation. However, US also have limitations and MRI is needed in most neonates with (suspected) parenchymal brain injury and/or neurological symptoms (van Wezel Meijler et al., 2010).

\section{Principles of sonographic evaluation and Doppler investigations}

\subsection{Cranial ultrasound technique in HIE}

Imaging findings in HIE are highly variable and depend on a number of factors, including brain maturity, severity and the duration of insult, and the type and timing of imaging studies. Early imaging findings can be subtle and are often overlooked. Therefore, it is essential to be familiar with the different patterns of injury that may be observed and to pay attention to the areas that are most likely to be injured after asphyxia when interpreting studies performed in asphyxiated infants with suspected HIE (Epelman et al., 2010; Huang \& Castillo, 2008). As recent US studies show modern cranial US is required to detect these early subtle findings (Epelman et al., 2010).

Cranial US begins with basic grey-scale imaging using the linear-array transducer via the anterior fontanel in the coronal and sagittal planes (Epelman et al., 2010; Lowe \& Bailey, 2011a). Typically, six to eight coronal images are obtained beginning at the frontal lobes just anterior to the frontal horns and extending to the occipital lobes posterior to the lateral ventricle trigons. The transducer is then rotated 90 degrees, and approximately five images are obtained including a midline sagittal view of the corpus callosum and cerebellar vermis in addition to the bilateral parasagittal image beginning in the midline and progressing laterally through the peripheral cortex. The structure and echogenicity of the brain is evaluated to establish normality through the anterior fontanel (Lowe \& Bailey 2011a). The size and the configuration of the frontal horns of the ventricles, the interhaemispheric fissure and the subarachnoidal space, the visualization of the normal structures (including sulci), the existence of haemorrhages and parenchymal echodensities, the presence, location and size of cystic degeneration will be examined (Ilves et al. 2009a; Rutherford et al., 1994). The ventricular size is measured as the greatest distance perpendicular to the ventricular axis (the greatest axis of the lateral ventricle on the coronal scan), and the maximal interhemispheric distance and the maximal width of the subarachnoideal space on the coronal scan are also measured (Liao et al., 1986).

To complete the modern head US, screening images via other supplemental fontanels and high-resolution linear images are needed (Lowe \& Bailey, 2011a). An attempt must be made to visualize as much as possible of the central and peripheral structures of the brain using multiple acoustic windows, such as the anterior and the posterior fontanels, as well as views through the temporal, mastoid and occipital areas. The angle of the transducer must be varied in an attempt to evaluate the periphery of the brain with particular attention to the subcortical white matter and the grey-white matter differentiation in as much of the cerebral hemispheres as possible (Epelman et al., 2010). The visualization of the cerebellar hemispheres is optimised by obtaining images through the right and left mastoid fontanels, the technique of which has been shown to improve the detection of posterior fossa haemorrhages. Finally, the completion of the modern cranial US requires switching from the 
curved - to a linear -array transducer, which allows high-resolution imaging of the brain with the detailed interrogation of the subarachnoid space and superficial cortex as well as deeper brain structures. Linear images can be adjunctively obtained via any fontanel (Epelman et al., 2010).

North \& Lowe describe some basic cranial US principles, which are helpful in interpretation of the findings, in 2009 (North and Lowe, 2009). First, the grey matter tends to be hypoechoic and the white matter tends to be hyperechoic. When this pattern is reversed, abnormality is indicated. Second, the normal brain is always symmetric, but symmetric findings are not always normal. This principle can avoid overlooking symmetric abnormalities such as bilateral hyperechoic thalami which can develop after thalamic ischemia or infarct during HIE (Huang \& Castillo, 2008; North \& Lowe, 2009). A third principle involves the visualization of all the layers of the normal cortex: the superficial pia mater should be seen as a thin well-defined hyperechoic layer overlying the hypoechoic cortical grey matter, which in turn overlies the hyperechoic white matter (Lowe \& Bailey, 2011a; North \& Lowe, 2009). Failure to distinctly visualize all these normal layers is helpful to identify the areas of abnormality, such as focal haemorrhage or infarct. Fourth, the periventricular white matter is normally homogeneous in echogenicity as is equal to or less echogenic than the adjacent chorioid plexus (Lowe \& Bailey, 2011a; North \& Lowe, 2009). Asymmetric or heterogenic increase echogencity of the periventricular white matter suggests an abnormality, as can occur with developing periventricular leucomalacia. The enlargement of liquor spaces and multicystic encephalomalacy can develop as early as after the first week of life in infants with severe HIE (Ilves et al., 2009a).

\subsection{Cerebral Doppler ultrasound technique}

After viewing cranial structures with the grey-scale US colour Doppler is switched on to screen vascular structures (North \& Lowe, 2009). Colour, spectral, and power Doppler imaging can be performed in the coronal and transverse plane via the anterior or the temporal fontanels, respectively. Power Doppler is used to screen for regions of hyper- or hypovascularity (Epelman et al., 2010; Lowe \& Bailey, 2011). Colour Doppler abnormalities include changes in the RI on spectral tracings and abnormalities of flow velocity in the venous sinuses and arteries. The choice which fontanel is used is based on convenience as well as which vessels the operator wishes to visualize. Colour Doppler images via the posterior fontanel or foramen magnum can also be used to screen for patency of the transverse sinuses (Epelman et al., 2010).

At first, the arterial system is assessed for patency and resistance to flow by obtaining a colour Doppler image of the circle of Willis (Lowe \& Bailey, 2011a). The colour images via the anterior or temporal fontanel are used to localize the middle cerebral artery (MCA), the anterior cerebral artery (ACA), the internal cerebral artery (ICA) or the basilar artery (BA) and to obtain special tracing with velocity curves and the resistance index measurements (Ilves et al., 2008). After the arterial system, the venous system is evaluated with grey-scale US and Doppler techniques to document the patency of the sagittal sinus and the vein of Galen in the sagittal plane (Lowe \& Bailey, 2011; Epelman et al., 2010).

During colour Doppler studies systolic, diastolic and mean velocities and the resistance index are evaluated using spectral Doppler tracing in the major peripheral vessels: ACA, 
MCA, ICA and BA. Care must be taken to visualize as much as possible of each of these arteries to accurately determine the insonation angle. The angle between the estimated direction of blood flow and the Doppler beam must be as low as possible to accurately measure the velocity, suggested less than 20 or less degrees, therefore the evaluation of MCA is suggested via the temporal approach and BA, ACA and ICA via the anterior fontanel. Guided by the velocity signal, displayed on an oscilloscope and an audio signal, the highest possible velocities must be used in the range-gated mode. After a stable velocity recording over 20-30 consecutive beats are received, and at least the 3-5 consecutive waveforms with the highest amplitude recorded can be analysed for: (1) the peak systolic flow velocity (Vs); (2) the end diastolic peak flow velocity $(\mathrm{Vd})$ and (3) the time-mean of the maximum velocity envelope curve (TAMV) and the time averaged mean velocity (TAV), i.e. the integral of the mean frequencies over at least 3-5 complete pulses. The resistance index $(\mathrm{RI})$ is calculated according to the formula $\mathrm{RI}=(\mathrm{Vs}-\mathrm{Vd}) / \mathrm{Vs}$.

For the measurement of BFV in cerebral arteries, the ACA is visualised in the sagittal plane through the anterior fontanel, and the signals are recorded from the point midway between the inferior-most border of the corpus callosum and the vessel's origin from the circle of Willis (Evans et al., 1988; Hayashi et al., 1992; Ilves et al., 2008). The BA is visualized in the sagittal plane just before the pons. The ICA is found in the coronal plane in the base of the skull just below the corner of the sella in the pars petrosa, where the vessel is oriented towards the scanner (Hayashi et al., 1992). The MCA is easy to visualize through the temporal bone in the region above the zygomatic arch in the fold of the temporal lobe from the straight mid-portion of the artery (Evans et al., 1988; Ilves et al., 2008).

\subsection{Visceral Doppler ultrasound technique}

The majority of term infants after severe birth asphyxia develop disturbancies in other organs than the brain (Martin-Ancelet al., 1995, Wayenberg et al., 1998; Shah et al., 2004). The redistribution of the blood to maintain the perfusion of the brain during asphyxia causes long-lasting changes in the blood flow in visceral organs, first of all in kidneys and intestine (Ilves et al., 2009). To evaluate the visceral blood flow changes and possible development of multiorgan failure in HIE patients, the abdominal organs must also be investigated. Kidneys can be scanned from the dorsolateral view, and the size, structure and echogenicity of the kidneys are evaluated to establish normality. The BFV in the renal artery (RA) can be visualized by placing the transducer in the right dorsolateral area of the flank below the costal arch and the sampling volume placed in the proximal portion of the vessel with a simultaneous viewing of the abdominal aorta (Adriani et al., 2001; Agata et al., 1994; Ilves et al., 2008). The origin of the coeliac artery (CA) and the superior mesenteric artery (SMA) is localized from the aorta in a longitudinal plane and the sampling volume is placed in the proximal SMA and CA (Agata et al., 1994; Ilves et al., 2008; Weir et al., 1995).

\subsection{Neonatal US technique}

Neonates can be usually examined without sedation while asleep or in the awake-quiet state with eyes closed and performing no gross body movements, which can disturb the evaluation of the velocity curves. Whenever restlessness occurs, the measurements of the blood flow velocity can be taken only after the infants are properly soothed and quiet. Low cyclical variations in the cerebral BFV, dependent on the sleep state, have been observed in 
term neonates with significantly greater amplitude during quiet sleep (often used in older ages as non rapid eye movement sleep-NREM sleep) compared to active sleep (REM sleep). However, no difference in the median cerebral BFV was observed in different sleep states (Ferrarri, et al., 1994). The BFV measurements of visceral organs must be performed at least 60-90 min after feeding as feeding increases the BFV to CA and SMA (Coombs et al., 1992; Martinussen et al., 1994;).

The study must be performed as rapidly as possible to minimize adverse influences on the infant; however, experienced investigators usually perform the whole study less than 10-15 $\mathrm{min}$. The duration of the ultrasound exposure of one artery is suggested to be not more than $60 \mathrm{sec}$ and the output intensity not to exceed the suggested safety limit of $100 \mathrm{~m} \mathrm{~W} / \mathrm{cm}^{2}$.

The BFV and the RI are influenced by many factors, which must be taken into account during evaluation. The major regulatory mechanism for the cerebral blood flow is autoregulation (Pryds et al, 1990, 1991), but also PaCO2, the oxygen and blood glucose delivery and the total haemoglobin concentration level (Volpe, 2005).

The intracranial and visceral hemodynamics change dramatically after birth in healthy infants. A severe increase in the BFV and the decrease in cerebrovascular resistance take place during the first week of life with largest changes occurring within the first 24 hour as a part of neonatal adaptation after birth (Agata et al., 1994; Hayashi et al., 1992; Ilves et al., 2008; Kempley et al., 1996; Martinussen et al., 1994; Yildirim et al., 2005). Ductal close and progressive increase in the blood pressure may explain the observed increase in BFV and decrease in the RI in healthy infants (Agata et al., 1994; Hayashi et al., 1992; Ilves et al., 2008; Martinussen et al., 1994; Yildirim et al., 2005). Autoregulation of the cerebral blood flow is operative in a normal full term infant (Ilves et al., 2008), however a pressure-passive state of the cerebral circulation is observed in seriously asphyxiated full term infants Pryds et al., 1990, Ilves et al., 2008)

The resistance index is also influenced by the flow velocity, the blood volume, the presence of congenital cardiac anomalies and the peripheral vascular resistance. The RI becomes higher if the diastolic flow decreases. If the intracranial pressure exceeds systemic pressure impending diastolic cerebral blood flow, RI increases as it can happen during cerebral swelling (North \& Lowe, 2009). However, it is very important to keep in mind that the RI becomes unreliable in some cardiac anomalies with left to right shunts which can decrease the RI particularly in the case of persistent ductus arteriosus alone or combined with other cardiac anomalies like truncus arteriosus communis, aortopulmonary shunts, aortic valve insufficiency and also in some extra cardiac shunts like cerebral arteriovenous fistula or the arteriovenous malformation of the great vein of Galen (Lipman et al., 1982, Deeg 1989). The RI becomes lower in the infants with severe birth asphyxia with severe HIE (Ilves et al., 2009a, 2009b), but also in the infants with other causes of increase in diastolic flow as it happens in the infants with cerebral vascular dilatation resulting from acute hypoxia or ischemia of any cause (Lowe \& Bailey, 2011a).

\subsection{Sensitivity of neonatal US}

Modern US equipment with the increased image quality and resolution can effectively depict changes in the brain parenchyma in HIE patients (Epelman et al., 2010; Ilves et al., 2009a), in contrast to the experience with ultrasound maschines in pediatrics in the early 
nineties (Barkovich, 1992; Stark \& Seibert, 1994). If compared to MRI, the sensitivity for modern US was 100\% (CI: 94.1-100), specificity 33.3\% (CI: 7.5-70), positive predictive value

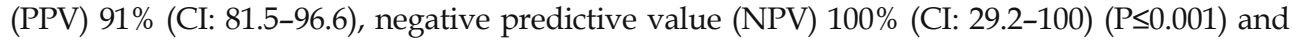
accuracy $95.7 \%$ (Epelman et al., 2010). Because US is operator-dependent, the importance of the aggressive US technique cannot be underestimated in the success of the US findings. The depiction of the lesions by US varies from subtle to diffuse changes in the echogenicity of the brain parenchyma. The subtle changes are often best appreciated during real-time imaging and it is therefore essential for the operator to be fully familiar with subtle changes in echogenicity and the areas where they can be visualized. Such aggressive technical approach showed that US has a high sensitivity and accuracy for documenting parenchymal abnormalities and enabled us to show at least one US abnormality in all 61 neonates with encephalopathy who had an abnormal MRI. There were no false negative US examinations (NPV $=100 \%$ ), which might be interpreted to mean that a negative US should obviate the need for an MRI (Epelman et al., 2010). However, in many cases MRI revealed more extensive and florid injury, suggesting that encephalopathic neonates indeed benefit from MRI. Although MRI is a gold standard, many of these children are too sick to be transported to the MRI suite or to tolerate the examination and in these cases a thorough US examination is invaluable.

\section{Clinical description of hypoxic-ischemic encephalopathy}

\subsection{The stages of hypoxic-ischaemic encephalopathy}

The children born at term with neonatal encephalopathy after birth asphyxia represent a heterogeneous group with respect to etiological factors, clinical symptoms, and outcome (Lindström et al., 2008). The causes of HIE can be separated into antepartum, intrapartum, and postpartum factors. In most cases, HIE in term neonates is associated with antepartum risk factors alone (including maternal hypotension, infertility treatment, multiple gestation, prenatal infection, and thyroid disease) or antepartum factors in combination with intrapartum. Intrapartum factors alone (including forceps delivery, breech extraction, umbilical cord prolapse, abruptio placenta, tight nuchal cord, and maternal fever) are responsible for a small minority of the cases of HIE and only $10 \%$ of the cases of HIE in term neonates are associated with postnatal complications such as severe respiratory distress, sepsis, or shock (Ferriero, 2004).

Traditionally based on the severity of asphyxia and HIE, the children are described to have a mild, moderate or severe stage of HIE. Clinical signs and symptoms of neonatal HIE can be non-specific at birth and usually evolve over a period of days (Ferriero, 2004), but data suggest that infants at the highest risk for having suffered severe HIE can be identified with the reasonable reliability based on clinical findings. These findings include the evidence of intrapartum distress (foetal heart rate abnormality), severe foetal academia, severe functional depression (indicated by a low 5-minute Apgar score), the need for resuscitation in the delivery room, an abnormal early neurologic examination, and an abnormal electroencephalogram (Shalak \& Perlman, 2004). In the first hours following a severe insult, neonates may demonstrate depressed consciousness, periodic breathing with apnoea, or bradycardia. Hypotonia may be present, particularly if there has been an injury to the cortical regions, and seizures may occur in the cases of severe asphyxia. Sarnat and Sarnat (1976) introduced an assessment of the severity of asphyxia in term infants on the basis of the clinical symptoms developing during the first days after birth (Sarnat \& Sarnat, 1976). 


\begin{tabular}{|c|c|c|c|}
\hline & $\begin{array}{l}\text { Mild HIE } \\
\text { Stage I }\end{array}$ & $\begin{array}{l}\text { Moderate HIE } \\
\text { Stage II }\end{array}$ & $\begin{array}{l}\text { Severe HIE } \\
\text { Stage III }\end{array}$ \\
\hline $\begin{array}{l}\text { 1. Level of } \\
\text { consciousness }\end{array}$ & Hyper alert & $\begin{array}{l}\text { Lethargy or } \\
\text { obtunded (difficult } \\
\text { to rouse) }\end{array}$ & $\begin{array}{l}\text { Stupor or coma } \\
\text { (cannot be aroused) }\end{array}$ \\
\hline \multicolumn{4}{|l|}{$\begin{array}{l}\text { 2. Neuromuscular } \\
\text { control }\end{array}$} \\
\hline Muscle tone & Normal & Mild hypotonic & Flaccid \\
\hline Posture & $\begin{array}{l}\text { Mild distal } \\
\text { flexion }\end{array}$ & $\begin{array}{l}\text { Strong distal } \\
\text { flexion }\end{array}$ & $\begin{array}{l}\text { Intermittent } \\
\text { decerebration } \\
\text { (extension) }\end{array}$ \\
\hline \multicolumn{4}{|l|}{$\begin{array}{l}\text { 3. Complex (primitive } \\
\text { reflexes) }\end{array}$} \\
\hline Suck & Normal/weak & Weak or absent & Absent \\
\hline Moro (startle) & $\begin{array}{l}\text { Strong, low } \\
\text { threshold }\end{array}$ & $\begin{array}{l}\text { Weak, incomplete, } \\
\text { high threshold }\end{array}$ & Absent \\
\hline Tonic neck & slight & strong & Absent \\
\hline \multicolumn{4}{|l|}{ 4. Autonomic Function } \\
\hline Pupils & mydrias & miosis & $\begin{array}{l}\text { Variable, often } \\
\text { unequal, poor light } \\
\text { reflex, fixed, dilated }\end{array}$ \\
\hline Heart rate & Tachycardia & Bradycardia & Variable \\
\hline 5. Seizures & None & $\begin{array}{l}\text { Common (focal or } \\
\text { multifocal }\end{array}$ & $\begin{array}{l}\text { Frequent/difficult to } \\
\text { control }\end{array}$ \\
\hline Electroencephalogram & Normal & $\begin{array}{l}\text { Early: low voltage } \\
\text { continuous delta } \\
\text { and theta } \\
\text { Later: periodic } \\
\text { pattern (awake). } \\
\text { Seizures: focal } \\
\text { spike and wave }\end{array}$ & $\begin{array}{l}\text { Early periodic } \\
\text { pattern with } \\
\text { isopotential phases: } \\
\text { Later: totally } \\
\text { isopotential }\end{array}$ \\
\hline Duration & Less than $24 \mathrm{~h}$ & 2-14 days & Hours to weeks \\
\hline
\end{tabular}

Table 1. Clinical stages of hypoxic-ischemic encephalopathy in the full-term newborn infant modified from Sarnat and Sarnat (Sarnat \& Sarnat, 1976)

\subsection{The pathophysiology of HIE}

The perinatal brain can be deprived of oxygen supply by two major pathogenetic mechanisms: hypoxemia and ischemia. Hypoxemia and ischemia can occur because of an event either before and/or during delivery, such as a nuchal cord, placenta previa, abruptio placenta, prolapsed or compressed cord, ruptured uterus, and/or obstetric accident. These conditions can lead to a reduced oxygen and/or blood flow to the infant. Not all the cases of the hypoxic-ischemic insult before and/or during labour will result in HIE. On the other hand in severe cases following the termination of the insult, a cascade of deleterious events results in the development of HIE and in cell death. 
The principal pathogenetic mechanism, underlying most of the neuropathology, attributed to intrapartum hypoxia-ischemia, is the impaired cerebral blood flow, which is most likely to occur because of the interruption in the placental blood flow and gas exchange; it is often referred to as "asphyxia" or severe foetal acidemia. The latter is defined as a foetal umbilical arterial pH level of below 7.00 (Perlman, 2006). With prolonged hypoxemia, cardiac hypoxia occurs, leading to the diminished cardiac output and, ultimately, to brain ischemia. Thus, the brain injury resulting from asphyxia is the consequence of ischemia superimposed on hypoxia. In fact, acute hypoxemia without superimposed ischemia is less likely to cause injury, unless the hypoxic state is prolonged (Biagas, 1999; Huang \& Castillo, 2008).

Severe and prolonged hypoxia and ischemia of any organ will result in cell death and tissue damage, the brain is especially sensitive to a decrease in the cellular oxygen supply (Fellman \& Raivio, 1997). The more severe the hypoxia-ischemic insult, the greater the "primary neuronal death" will be during asphyxia (Fellman \& Raivio, 1997).

After resuscitation, which may occur in utero or postnatally in the delivery room, cerebral oxygenation and perfusion is restored (Perlman, 2006). The restoration of blood flow and oxygen delivery after asphyxia is necessary for organ survival, but is critical, because damage may progress during this "reperfusion period". Therefore, in survivors brain injury is an evolving process that is initiated during the insult and extends long into a recovery period (Fellman \& Raivio, 1997; Perlman, 2006). If the initial energy failure during asphyxia is sufficiently prolonged and severe, the reduction in the cerebral blood flow and oxygen delivery is capable of triggering a cascade of deleterious biochemical events at the cellular level leading to secondary delayed cell death without continuing energy failure (Fellman \& Raivio, 1997; Perlman, 2006; Shadid et al., 1998). However, the process of energy failure recurs from 6 to 48 hours later in a second phase of injury (Perlman, 2006), characterised by a progressive decrease in high energy phosphate levels, in spite of the normal substrate supply, the normal blood pressure and the acid base status as shown in human infants (Wyatt et al., 1989) and newborn piglets (Lorek et al., 1994). In the case of the development of the secondary energy failure, survival without permanent brain damage is very unlikely. In a human infant, the severity of the second energy failure is correlated with adverse neurodevelopmental outcomes at 1 and 4 years (Roth et al., 1997). So the onset of ischemic cell changes during reperfusion is delayed and is called the delayed or "secondary cell death" phenomenon (van Bel et al., 1998).

Hypoxic ischemic insults may lead to neuronal cell death, to necrosis or apoptosis, or both, depending on the severity of the initial insult, the local environment of the affected region of the brain, and the maturational state of the brain. The intensity of the initial insult may determine the mode of death, with severe insult resulting in necrosis, whereas milder insults result in apoptosis (Bonfoco et al., 1995). Whether a particular cell undergoes necrosis or apoptosis may depend upon many factors: the severity of the cellular insult, the cellular energy reserves, and the events associated with delayed energy failure, the ability of the mitochondria to recover function upon resuscitation or trophic support from neighbouring cells (Edwards et al., 1997). Necrosis is a passive process and is characterized by cell swelling, disrupted cytoplasmic organelles, membrane disintegration, cell rupture, release of intracellular contents, and as a consequence, inflammation and phagocytosis. Apoptosis 
is an active process distinguished from necrosis by the presence of cell shrinkage, nuclear pyknosis, and relative preservation of the cellular membrane, genomic fragmentation and death without inflammation (Edwards et al., 1996).

The goal of the management of the newborn infants who have sustained a hypoxic-ischemic insult is to early identify the infant at the highest risk for evolving injury, facilitate adequate perfusion and nutrients to the brain and to provide specific interventions during the short time period when interventions might be still efficacious in reduction of developing brain damage (Perlman, 2006).

\section{The pathogenesis of multiorgan failure in perinatal asphyxia}

The interruption of the placental blood flow during labour and the decompensation of the circulatory responses lead to systemic hypotension and ischemia in different organs. The key to the protection of the central nervous system during the hypoxic-ischaemic insult is the adaptation of the foetal cardiovascular system, which by increasing the cerebral blood flow maintains cerebral oxygen metabolism (Koehler et al., 1985). The compensatory cardiovascular response of the foetus to hypoxemia is an increase of the arterial pressure caused by the increased systemic vascular resistance and the initial increase of cardiac output (Koehler et al., 1985). The redistribution of cardiac output - with an increased flow to the brain, heart, and adrenal glands at the expense of the flow to the kidneys, gut and skin is a major protective mechanism to maintain the perfusion of vital organs during asphyxia and can lead to a visceral organ as well as at last cerebral injury (Koehler et al., 1985; Perlman, 2006; Stola \& Perlman, 2008).

This redistribution of blood can lead to ischemic damage in different organs with multiple organ failure developing in 50-60\% of severely asphyxiated infants (Wayenberg, et al., 1998). Early BFV changes have been documented in critically ill infants following birth asphyxia in the cerebral (Bennhagen et al., 1998; Ilves et al., 2004, 2009a, 2009b), renal or superior mesenteric arteries and the celiac artery (Koc et al., 1998; Luciano et al., 1998).

The central nervous system is disturbed in $70 \%$ of infants after severe birth asphyxia (Martin-Ancel et al., 1995) and the severity of HIE predicts the risk of death and long-term neurodisability (Ilves et al., 2004, 2009a; Lindström et al., 2008; Sarnat \& Sarnat, 1976). However, asphyxia is likely to cause disturbances in a number of organ systems other than the brain. Renal involvement occurred in $40-50 \%$, pulmonary involvement in $25 \%$, cardiac involvement in 25-30\% and gastrointestinal involvement in 30\% of the cases of asphyxiated term infants (Martin-Ancel et al., 1995; Wayenberg et al., 1998). Others show a high proportion of infants with renal, pulmonary, cardiac and liver dysfunctions both in with a good neurodevelopmental outcome (58-88\% of infants) and with an adverse outcome (64$86 \%$ of infants) (Shah et al., 2004).

As the duration and severity of asphyxia may be difficult to estimate and the compensatory capacity of the foetus and newborn is unknown, it is difficult to predict the severity of organ damage immediately after birth. The BFV findings have a clinical relevance in interpreting the cardiovascular adaptation of distressed newborn infants with a decompensation of circulatory responses and the possible development of organ failure (Ilves et al 2009b). 


\section{Acute changes in sonography}

\subsection{Acute changes in grey-scale sonography}

\subsubsection{Factors influencing US findings in HIE patients}

Factors such as brain maturity, the duration and severity of insult, and the type and timing of imaging studies all influence radiological findings in HIE.

The sites in the brain that tend to be most vulnerable to hypoxic injury will be determined largely by the maturity of the brain (Huang \& Castillo, 2008). Severe hypoxia-ischemia in both preterm and term neonates preferentially damages the deep grey matter, with the perirolandic involvement more frequently observed in the term neonates. Less profound insults result in intraventricular haemorrhages and periventricular white matter injury in preterm neonates and parasagittal watershed territory infarcts in term neonates (Huang \& Castillo, 2008).

The duration of insult also seems to be a key determinant of the pattern of injury in HIE, since the insults of short duration usually do not result in brain injury. The episodes of severe hypoxia-ischemia result in a different injury pattern compared with less severe insults (Huang \& Castillo, 2008).

It is well known that global hypoxic-ischemic insults do not affect all brain structures uniformly and certain tissues in the brain are more likely to be injured and are injured earlier than others, a concept known as selective vulnerability. Evidence suggests that the observed patterns of injury reflect the dysfunction of selected excitatory neuronal circuits, which causes a complex cascade of deleterious biochemical events and, ultimately, selective neuronal death (Johnston et al., 2001). In infants with HIE the following areas a most susceptible to hypoxic-ischaemic injury: (a) the areas of the brain with the highest concentrations of glutamate or other excitatory amino acid receptors (primarily located in the grey matter) are more susceptible to the excitotoxic injury following the hypoxicischemic insult; (b) the areas of the brain with the greatest energy demands become energy depleted most rapidly during hypoxia-ischemia, and are therefore injured more easily and earlier; and (c) because of delayed cell death from apoptosis the injury may be expressed in full extent days and even months after the initial insult has occurred (Ilves et al., 2009; Huang \& Castillo, 2008).

Selective neuronal necrosis is the most common variety observed in neonatal HIE with necrosis of the neurons in a characteristic widespread distribution. The neurons of the cerebral cortex are the most vulnerable, most often hippocampus. However, the involvement of diencephalon, basal ganglia (neurons of the caudate, putamen and globus pallidus) and the thalamic injury and even brainstem occur. The mechanism of the neuronal injury is related to ischemia rather than hypoxia alone (Volpe JJ 2008). Regional vascular factors play a certain role because of neuronal injury is more marked in vascular borderzones during ischemia, in the deths of sulci and in parasagittal cerebral cortex (Volpe JJ 2008).

Less severe insults of partial asphyxia result in a different pattern of injury. The experiments performed in animal models have demonstrated that the episodes of prolonged foetal hypoxia result in shunting of blood to vital brain structures, such as the brainstem, thalami, basal ganglia, hippocampus, and cerebellum, at the expense of less metabolically active structures as the cerebral cortex and the white matter (Ashwal et al., 1980). Therefore, the 
brainstem, cerebellum, and the deep grey matter structures are generally spared from injury in mild to moderate hypoxic-ischemic insults, because of autoregulatory mechanisms are able to maintain perfusion to these vital areas of the brain (Barkovich, 2005); however, more prolonged insults result in injury to the intervascular watershed zones, which are relatively hypoperfused as a result of this shunting during a pressure passive state of cerebral circulation (Barkovich, 2005). This injury is visible as a symmetric damage but may be more prominent in one hemisphere than the other. The posterior aspects of the cerebral hemispheres, especially the parietal-occipital regions, are more affected than the anterior (Volpe JJ 2009).

\subsubsection{Acute US findings}

The US abnormalities in HIE patients can be found in the cortical grey matter, in the areas of the subcortical or periventricular white matter, or in deep grey-matter structures, including basal ganglia, thalami and the brainstem (Eken et al., 1995; Epelman et al., 2010; Ilves et al., 2009a). US changes in HIE can be classified as peripheral and central.

\subsubsection{Peripheral brain abnormalities}

include changes in the grey-white matter differentiation (increased, absent or mixed) and changes in the echogenicity of the cortex and subcortical white matter (Figure 2b). Early US findings include a global increase in cerebral echogenicity and the obliteration of the cerebrospinal fluid (CSF)-containing spaces, suggesting diffuse cerebral oedema (Figure 2a). However, the small size of liquor spaces alone is not specific for brain oedema and slitlike ventricles can be seen in healthy newborns during the first 3 days of life (Ilves et al., 2009a). The size of the ventricles, the interhemispheric fissure and the subarachnoideal space is not different between controls and asphyxiated infants with different stages of HIE or with different outcome during the first 3 days after birth (Ilves et al., 2009a).

An increase of parenhymal echogenicity with partial or total obliteration of normally visible structures is correlated with severity of HIE: Although the phenomenon of increased echogenicity (the so- called "bright brain") is fully developed by the second-third day of life, the moderate to severe increase of parenchymal echogenicity as early as at the age of $12 \pm 2 \mathrm{~h}$ has a high sensitivity ( $88 \%$ ) for death or severe disability and can be an early predictor of permanent brain damage in asphyxiated infants (Ilves et al., 2009a). By the second-third day of life, the predictive value of the "bright brain" phenomenon can be as high as $90-100 \%$ (Babcock \& Ball, 1983). A strong correlation exists between the duration of the increase of parenchymal echogenicities and outcome at the age of 18 months. In infants with moderate HIE echogenicity gradually normalizes; long-lasting increase in parenchymal echogenicity (5-7 days and more) is a predictor of poor outcome (Babcock and Ball, 1983; Ilves et al., 2009a).

The power Doppler evaluation of the brain parenchyma is also valuable to determine the presence of hyperaemia or hypovascularity (Figure 2c). In the infants with hyperaemia of the brain parenchyma the prominence of the lenticulostriate vasculature and/or prominent cortical vessels can be observed. However, hyperaemia was a subjective evaluation and was noted as present in 19 of the 53 neonates with encephalopathy (Epelman et al., 2010). The regions of hypovascularity can be seen in the areas of vascular occlusion or infarction (Lowe \& Bailey, 2011a). Cranial US, as well as CT, is of limited use in the detection of superficial cortical and subcortical watershed zone injuries, given their location relative to the calvaria. 
Therefore, MRI imaging is the modality of choice in term infants who experience partial asphyxial events which is more effective to identify these lesions (Figure 2g). Diffusionweighted images are the earliest to change, usually within the first $24 \mathrm{~h}$ (Barkovich, 2005). However, with the good technique described earlier, modern equioment and excellent experience in ultrasonongraphy are essential to detect parencymal echogenisities.

\subsubsection{Central brain abnormalities}

in infants with severe global asphyxia include changes in echogenicity of the deep grey matter (basal ganglia and thalami), brainstem and the periventricular white matter (Epelman et al., 2010) (Figure 2e). Severe asphyxial events in term neonates result in a primarily central pattern of injury involving the deep grey matter (putamina, ventrolateral thalami, hippocampus, dorsal brainstem, and lateral geniculate nuclei) and occasionally the perirolandic cortex. These areas of the brain are actively myelinating (an energy-intensive process) or contain the highest concentrations of NMDA receptors at term (Barkovich, 1992) and are, therefore, the most susceptible to neonatal HIE. The remainder of the cerebral cortex is generally spared or shows mild insults, since it is generally less metabolically active in the immediate perinatal period; however, with more prolonged insults, the remaining cortex will become involved, a finding that generally corresponds to a worse neurologic outcome (Barkovich, 2005). The presence of thalamic echogenicity generally suggests a more severe injury and correlates with a poorer outcome (Connolly et al., 1994; Eken et al., 1994). Hyperechogenicity in the thalamic/basal ganglia region (so-called "bright thalamus") takes time to develop, and a correct US diagnosis will not always be possible during the first $24 \mathrm{~h}$ of age unless there is an antenatal onset of the lesion (Eken et al., 1994). Hypovascularity and/or hyperaemia in basal ganglia can be followed in the infants with severe HIE by the power Doppler. Increased echogenicity in the basal ganglia, thalami, and brainstem is prolonged and is even readily apparent after 7 days after severe birth asphyxia (Babcock \& Ball, 1983; Hertzberg et al., 1987).

Less severe insults of partial asphyxia result in a different pattern of injury. The brainstem, cerebellum, and the deep grey matter structures are generally spared from injury in mild to moderate hypoxic-ischemic insults, since autoregulatory mechanisms are able to maintain perfusion to these areas of the brain (Barkovich, 2005); however, more prolonged insults result in the injury to the intervascular boundary (watershed) zones. If the normal pattern of the hypoechoic grey matter and the hyperechoic white matter is reversed, abnormality is indicated (Huang \& Castillo, 2008; North \& Lowe, 2009). Normal layers of cortex: the superficial pia mater should be seen as a thin well-defined hyperechoic layer overlying the hypoechoic cortical grey matter, which in turn overlies the hyperechoic white matter, will be difficult to distinct. Failure to distinctly visualize these normal layers is helpful to identify the areas of abnormality, such as focal haemorrhage or infarct. However, again MRI imaging is more effective to identify these lesions (Barkovich, 2005). The periventricular white matter hyperechogenicities, uni-or bilateral can be followed as more echogenic than the adjacent chorioid plexus (Lowe \& Bailey, 2011a; North \& Lowe, 2009).

\subsection{Acute changes in the Doppler sonography}

The use of cerebral arterial Doppler US during US evaluation performed in the first few days of life may improve sensitivity and specificity for brain injury, since the presence of 
diminished resistive indexes in the cerebral arteries has been associated with a poor clinical outcome, even in the absence of other US abnormalities (Stark, et al., 1994). Changes in BFV and metabolism after hypoxic-ischaemic insult are the potential mechanisms of subsequent damage during reperfusion (Fellman \& Raivio, 1997; Rosenberg, 1986).

\subsubsection{Initial cerebral hyperaemia}

In animal models, resuscitation after mild to moderate ischemia is accompanied by a period of initial hyperaemia (Rosenberg, 1986). Evidence exists that the initial hyperaemia is a prerequisite for functional recovery, at least following long periods of ischemia (Kangström et al., 1983). A severe hypoxic-ischaemic insult is followed by a failure to reperfuse ischaemic regions even after the restoration of the oxygen supply although the blood pressure is within the autoregulatory range. Failure to reperfuse ischaemic regions after the restoration of circulation is called the "no-reflow" phenomenon and is one of the potential mechanisms of extended injury during the period after ischemia. It is possible that not all structures of the brain are affected by the "no-reflow" phenomenon. In some structures, there may be the evidence of "reactive hyperaemia", whereas others may show perfusion defects (Kangström et al., 1983). Typically, these defects affect striatum, thalamus, and hippocampus, as well as frontal and parietal cortices after complete global ischemia. The duration of ischemia influence the condition of flow restoration in "no-reflow" areas, the longer the period of ischemia, the more structures were affected by the phenomenon in rats (Kangström et al., 1983).

\subsubsection{Delayed cerebral hypoperfusion}

Initial cerebral hyperaemia after the hypoxic-ischemic insult is followed by delayed cerebral hypoperfusion. A steady decrease of BFV 12 hours after asphyxia has been described in infants (Ilves et al., 2004; Shadid et al., 1998; van Bel et al., 1998) and in animal models (Kangström et al., 1983). It has been speculated that the delayed hypoperfusion may add a secondary ischaemic insult to the tissue, especially if the reduction in BFV is not matched to the metabolic rate (Kangström et al., 1983). The severity of posthypoxic hypoperfusion increases with the increasing duration of a preceding cerebral ischemia (Kangström et al., 1983). Among infants with severe birth asphyxia, babies with the severest stage of HIE demonstrated the greatest decrease in BFV (van Bel et al., 1998). We have shown that some asphyxiated infants mostly with moderate HIE have extremely low cerebral BFV velocities (below 3SD) with a high RI during the first day of life which is associated with poor prognosis (Ilves et al., 2004, 2009a, 2009b)(Figure 2d). This delayed postasphyxial cerebral hypoperfusion could be related to an excess of vasoconstrictor molecules (Fellman \& Raivio, 1997). Low cerebral blood volume during the first 28 days of life was described in a small group of infants probably with mild to moderate HIE, developing cerebral paralysis later (Fukuda et al., 2008).

\subsubsection{Delayed cerebral hyperperfusion}

Several authors have reported high BFV and significantly lowered RI in infants with severe HIE at the age of 24-72 h (Levene et al., 1989; Bennhagen et al., 1998; Ilves et al., 2009 a, 2009b) (Figure 2f). BFV has been recorded higher in infants with permanent brain damage 
during the first days of life (Pryds, 1991; Ilves et al., 2009 a, 2009b). Severe increase in cerebral BFV and the decrease in RI take place in asphyxiated infants with severe HIE and a poor prognosis by the second half of the first day, being most severe during the first 3 days (Bennhagen et al., 1998; Ilves et al., 2009a; Meek et al., 1999; Pryds et al., 1990). The maximum BFV values are registered at the age of 36-71 $\mathrm{h}$ (Ilves et al., 2009a) decreasing gradually by the age of 1 week (Figure 1). However, in very severe cases with a poor prognosis high BFV is seen already at the age of $12 \mathrm{~h}$ or ealier suggesting a very short therapeutic window in severely asphyxiated infants (Ilves et al., 2009a). Animal models have also shown that initial posthypoxic hypoperfusion is followed by delayed vasodilatation, increased BFV and cerebral energy failure $24-72 \mathrm{~h}$ after the hypoxic-ischemic insult (Lorek et al., 1994). In this situation, dissociation exists between the cerebral metabolic rate and the over-abundant BFV relative to the metabolic needs of the brain tissue, the socalled luxury perfusion (Levene et al., 1989). Markedly high BFV despite isoelelctric EEG activity is found in these infants (Pryds, 1991). The BFV was higher, but the cross-brain oxygen extraction was lower in asphyxiated infants who died, compared to the neonates who survived with a normal neurologic outcome (Frewen et al., 1991). Delayed hyperaemia often occurs as a focal phenomenon, but may also be generalised (Levene et al., 1989).

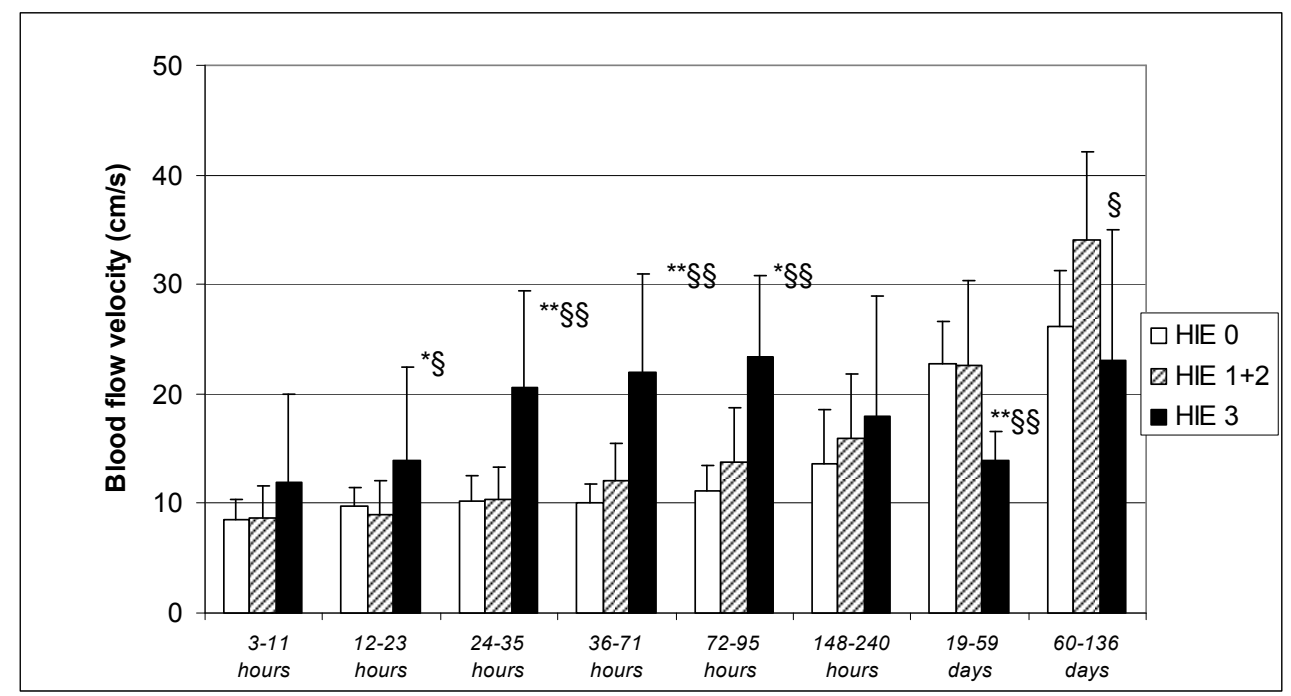

Fig. 1. Mean cerebral blood velocity (TAV) in a anterior cerebral artery infants with HIE with HIE 0 ( $\mathrm{n}=115$ infants); HIE I+II ( $\mathrm{n}=58$ infants); HIE III ( $\mathrm{n}=25$ infants); $* \mathrm{p}<0.05$ HIE III vs. HIE I+II; **p < 0.001 HIE III vs. HIE I+II; $\$ p<0.05$ HIE III versus HIE 0; $\S \S p<0.001$ HIE III versus HIE

In 1986, Archer et al. (Archer, et al., 1986) introduced the cerebral vascular resistance index (RI) for predicting clinical outcome from $24 \mathrm{~h}$ of age in the infants with moderate or severe HIE (Figure 2f). In severe HIE patients the RI below 0.55 had a positive predictive value (PPV) for death or disability of $75 \%$ and a negative predictive value (NPV) of $100 \%$. Bennhagen and co-workers have found the RI increased in infants with HIE during the first 
day of life developing low RI by the second day of life (Bennhagen et al., 1998). In some infants with poor prognosis, the RI is already significantly lower compared to the control group as early as at the age of 2-11.9 h (Ilves et al., 2009a). Although the low RI soon after birth had a poor outcome, the high RI was found in most infants who subsequently had a poor outcome (Eken et al., 1995). RI was independent of the angle between the ultrasound beam and the blood flow in the artery being examined and could be obtained from any intracerebral arter giving a good-quality signal.

The reason for this cerebral hyperaemia and the low RI during the second-third day after asphyxia may be a severe vasoparalysis, a form of irreversible cerebral vascular injury (Levene et al., 1989; Pryds et al., 1990; Meek et al., 1999). In infants with birth asphyxia hyperperfusion is thought to be a sign of permanent brain damage with a poor neurodevelopemental prognosis (Bennhagen et al., 1998; Ilves et al., 2009a; Meek et al., 1999; Pryds et al., 1990). The severity of vasoparalysis and cerebral hyperaemia is thought to correlate with the degree of brain injury and presumably the severity of asphyxia insult (Levene et al., 1989; Pryds et al., 1990). The infants with the poorest neurologic outcome (isoelectric EEG and death) had the highest values for BFV and no cerebrovascular autoregulation or $\mathrm{CO} 2$ reactivity; the infants with the burst suppression EEG and moderate to severe brain injury has slightly elevated values of BFV and impaired autoregulation, but a sustained reactivity to Pa CO2 (Pryds et al., 1990). The infants without an evidence of brain injury had normal values for BFV, intact autoregulation and reactivity to $\mathrm{PaCO} 2$ (Pryds et al., 1990). The mechanism of such luxury cerebral perfusion following ischaemic brain injury is still unclear. The neuronal disruption causing release of vasoactive substances such as adenosine and lactate, or of excitatory amino acids (Pryds, 1991), irreversible cerebral vascular injury with a complete loss of tone in resistance vessels may play a role in the pathogenesis of delayed hyperaemia (Fellman \& Raivio, 1997; Levene et al., 1989; Pryds et al., 1990).

Severe increase in the cerebral blood flow velocity and the decrease in RI have been described in infants with severe HIE/ poor outcome (Eken et al., 1995; Ilves et al., 2004, 2009a; Levene et al., 1989; Pryds et al., 1990; Stark et al., 1994). However, recent studies show that even in the infants with mild / moderate HIE the mean cerebral BFV was higher than in the control group in all the cerebral arteries during the period 36-120 h (Ilves et al., 2009a). Moderately but statistically significantly increased mean cerebral BFV in the infants with mild-moderate HIE from $36 \mathrm{~h}$ lasting as late as 7-10 days after asphyxia can indicate the ongoing subacute process of cell damage in these infants. Although only a small number (2 of 58 infants) with moderate HIE developed severe disability (Ilves et al., 2009a) at the age of 18 months, recent data in the long-term follow-up study of the infants with moderate HIE show a high rate of cognitive dysfunctions in these children (Lindström et al., 2008).

All the previously published literature on RI and BFV and the prediction of outcome has been obtained on infants at normal temperature. It is possible that hypothermia will affect the cardiovascular system in the ways that might change RI (Elstad et al., 2011; Thoresen \& Whitelaw, 2000). Elstad with cowoorker have described: "Among the cooled infants, the PPV of any RI below 0.55 for poor outcome was only $60 \%$. This is lower than the PPV in any previous studies in infants with HIE treated at normothermia (median value $84 \%$ ). The initial data show that RI $>0.55$ is a good negative predictor, but RI below 0.55 is not as good 
positive predictor of poor outcome as reported earlier in normothermic infants. These findings mean that infants, who would have been predicted to have poorer outcome at normothermia, have better outcome treated when cooled. A low RI is significantly less predictive of poor outcome during hypothermia than normothermia. The lower PPV of RI may be because hypothermia affects cerebral vasculature or protects the brain solely at a molecular and cellular level. Infants, who would have been predicted from their RI to have poorer outcome at normothermia, have better outcome when cooled" (Elstad et al., 2011). RI should never be used for prediction alone; it is only one piece of information to be put into the clinical puzzle. However, as ultrasound Doppler is safe, cheap and readily available, RI measurement is recommended on day 2 (24-48 h after birth) and three (48-72 h) for infants with HIE treated with hypothermia as RI is lowest at 48 h" (Elstad et al., 2011).

The animal model using contrast-enhanced ultrasound (CEUS) and MRI shows that both can detect an early temporal evolution of cerebral perfusion in perinatal hypoxia and resuscitation, reversible after 7 hours (de Lange et al., 2011). Hyperoxic resuscitation caused early decreased cerebral perfusion, not present in the normoxic group. These findings show that the combined use of CEUS can provide important diagnostic information and give new insights into perinatal vascular hypoxia mechanisms (de Lange et al., 2011).

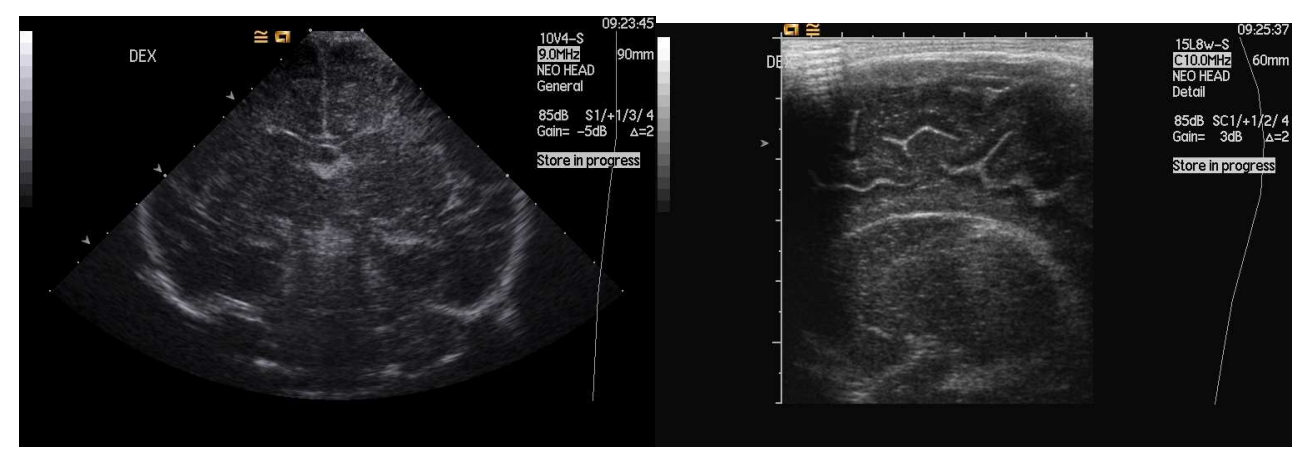

a

$\mathrm{b}$

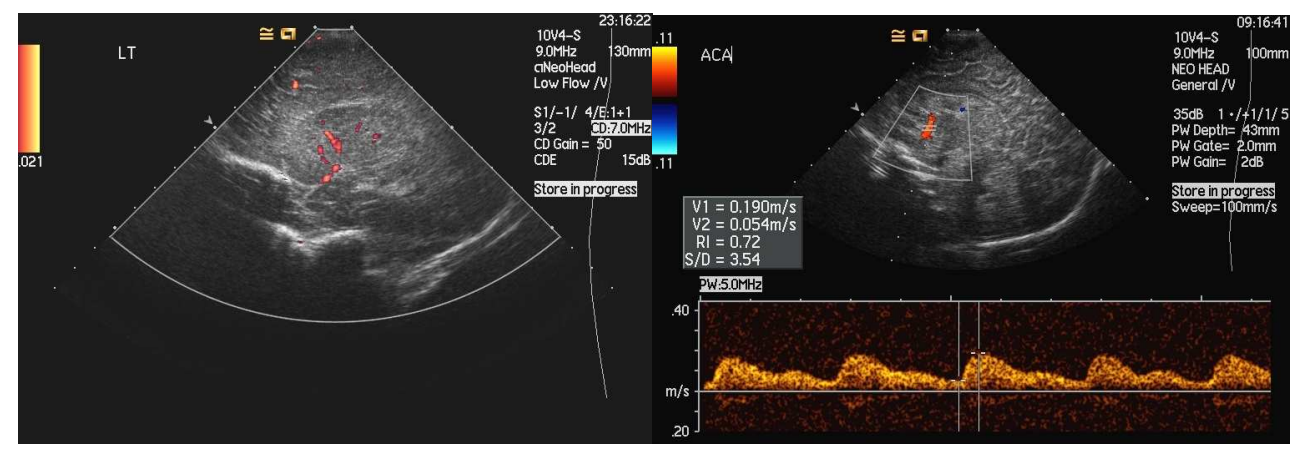

C

d 


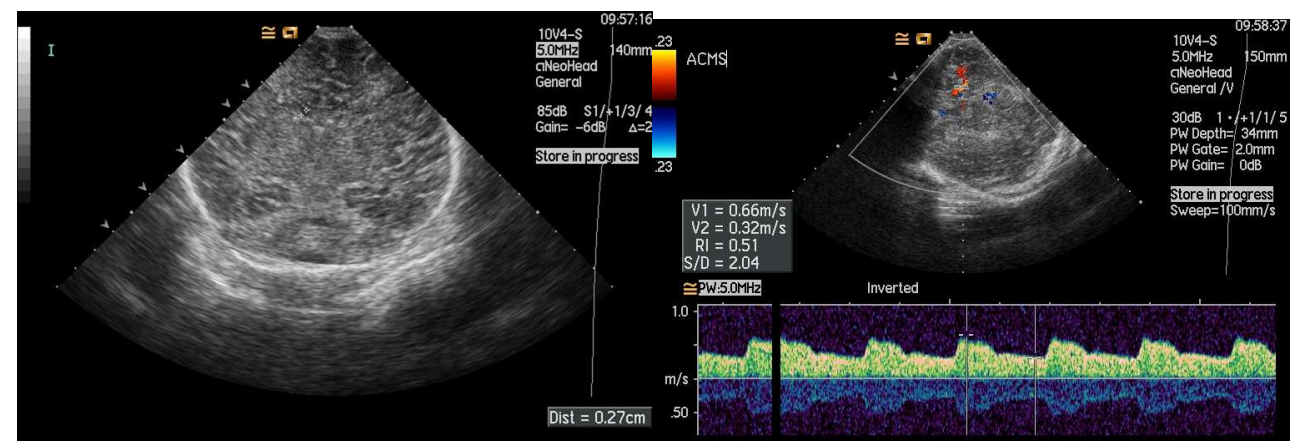

$\mathrm{e}$

f

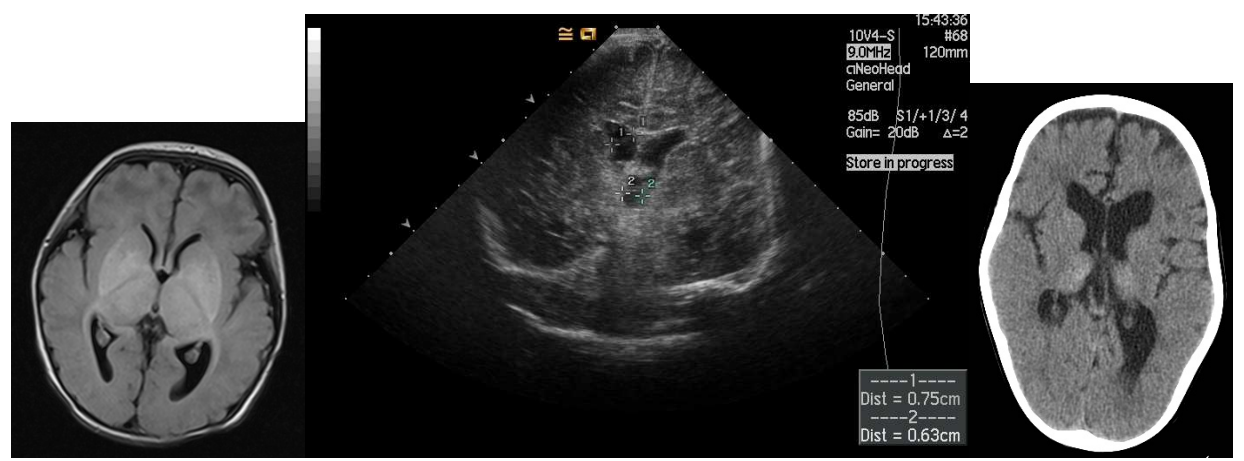

g

$\mathrm{h}$

i

a) Coronar US image shows ill-defined structures including basal ganglia, and slitlike ventricles at the age of $12 \mathrm{~h}$

b) Magnified sagittal view using linear transducer shows the accentuation of the grey -white matter differentiation with prominent sulci at the age of $12 \mathrm{~h}$

c) Left parasagittal view shows hyperaemia in the region of basal ganglia with power Doppler at the age of $12 \mathrm{~h}$

d) Colour Doppler evaluation shows a low cerebral blood flow velocity with normal resistance in the right anterior cerebral artery at the age of $12 \mathrm{~h}$

e) Coronar US image shows still ill-defined structures with general increase in echogenicty including basal ganglia, and still slitlike ventricles at the age of 3 days

f) Colour Doppler evaluation shows a high cerebral blood flow velocity with low resistance in the left medial cerebral artery at the age of 3 days

g) MRI FLAIR image with pathological signal intensity bilaterally in basal ganglia at the age of 8 days

h) Coronar US with moderately enlarged side ventricles and ill-defined basal ganglia at the age of 1 month

i) CT image with atrophy and increased attenuation in basal ganglia at the age of 3 years

Fig. 2. $12 \mathrm{~h}$ old girl born at 39 weeks of gestation with a history of perinatal asphyxia after total abruption placenta and the respective Apgar scores 1-2-3 at the age of 1-5-10 minutes with severe HIE who survived with cerebral paralysis, tetraplegia, seizures and bulbar paralysis 


\section{Long-term changes in sonography}

\subsection{Long-term changes in gray-scale sonography}

Late findings of US include the resolution of the initial findings and the progressive prominence of the ventricles and the extraaxial CSF containing spaces, likely due to atrophy and the development of multicyctic encephalopathy.

By the age of the 7 days the size of the ventricles, the interhemispheric fissure and the subarachnoideal space were significantly increased in the infants with a severe HIE/poor prognosis compared to the infants with a mild to moderate HIE or the infants with a normal outcome/mild impairments respectively (Ilves et al., 2009a). By the age of 5 months the progressive enlargement of the size of the ventricles, the interhemispheric fissure and the subarachnoideal space occurred in the infants with a severe HIE/poor prognosis (Ilves et al. 2009a) (Figure 2h). The size of the ventricles and the interhemispheric fissure at the age of 21-159 days was significantly correlated with the severity of HIE and the psychomotor development at the age 18 months.

Multicystic encephalopathy developed in 18 of 25 infants with severe HIE, all had a poor outcome: 10 infants died and eight infants were with severe disability at the age of 18 months. Parenchymal cysts mostly in the frontoparietal region were first seen as early as at the age of 7 days in five infants, all died during the first month. In 12 infants with severe HIE cysts could be visualized between the age of 14-21 days and only in 1 of 18 infants the cysts were first seen after the age of 21 days (Ilves et al., 2009a). Small cysts are no longer visible by the age of 3 months, therefore it seems reasonable to perform US in the infants with a moderate or severe stage of HIE at the age of 1 month in order to detect all the infants with cystic degeneration (Ilves et al., 2009a).

The intensity of the initial insult may determine the mode of cell death resulting in necrosis in severe injury whereas milder insults result in apoptosis (Bonfoco et al., 1995). It is likely that the enlargement of the side ventricles and the appearance of the parenchymal cysts visible already by the age of 7 days in the infants who died can be the signs of rapid cell death and probably represent cell necrosis, which accounts for the significant proportion of the cell loss in asphyxiated infants (Bonfoco et al., 1995).

CT and MRI studies indicate the temporal profile of the signs of the brain swelling during the first week of life being most severe 36-72 hours after asphyxia (Rutherford et al., 1995; Yoxall \& Weindling, 1998) (Figure 2h). The infants with a severe HIE/poor prognosis and the progressive enlargement of the side ventricles and the subarachnoidal space with the development of parenchymal cysts during the first months of life have also suboptimal head growth during the first months of life (Ilves et al., 2009a). This enlargement of side ventricles progresses during several months (Ilves et al., 2009a). Decrease in the periventricular white matter has been described earlier in MRI studies in the infants older than 3 weeks (Rutherford et al., 1995). Serial head circumference investigations also show that the appearance of microcephaly may be delayed for more than 12 months (Cordes et al., 1994). The findings suggest that cell death can be long-lasting with on-going progressive cell loss days and may be weeks and months after asphyxia. Apoptosis that is aslower process can play a role in the long-lasting brain damage in the infants with severe asphyxia. This can indicate that neuroprotection probably must be lasting more than only first days after 
asphyxia. Therapeutic hypothermia for moderate to severe HIE's during the first days after asphyxia is currently the only clinically proven treatment for infants with neonatal asphyxia (Hoehn et al., 2008). The potential strategies to prevent or reduce reperfusion injury in asphyxiated infants probably need to include the interventions that target both processes: cell necrosis during the first days after asphyxia and apoptosis on going probably during the longer period after asphyxia.

\subsection{Long-term changes in Doppler sonography}

In normal infants and the infants with a mild/moderate HIE or good prognosis, steady increase in the mean cerebral BFV and the decrease in RI occurred in all the cerebral arteries during the first months of life (Ilves et al., 2008, 2009a; Kojo et al., 1996; Mercuri et al., 2000), probably reflecting the increasing cerebral blood flow during the first year of life. The infants in the control group and the infants with a mild/moderate HIE or good prognosis also showed steady head growth with no significant differences in the head circumference or the ventricle size between these groups during the first months of life. The steady increase in cerebral BFV in healthy infants appears to reflect the rising metabolic demand of the growing brain during the neonatal period (Kelner et al., 2003). The increase in blood flow has been shown during the first year of life, the cause of which can be rapid myelination and the explosive increase of the synapses with decrease in nerve cell density (Takahashi et al., 1999). The increasing demand for metabolic fuels during the first months after birth is found in the studies investigating cerebral glucose consumption using positron emission tomography (PET) and measuring cerebral oxygen consumption with NIRS (Chugani et al., 1986; Kinnala et al., 1996; Yoxall et al., 1998). This extreme increase in the mean BFV in infants with a severe HIES/poor outcome is temporary and the cerebral BFV gradually decreases after the first week of life (Ilves et al., 2009a). The findings are consistent with the studies of the cerebral glucose metabolism measured by PET in term infants with hypoxic-ischemic encephalopathy, showing hypermetabolism during the acute period 2-5 days after birth asphyxia (Blennow et al., 1995) and lower metabolism during the subacute period (at the age of 4-24 days) after asphyxia (Thorngren-Jerneck et al., 2001).

Such steady increase of the mean BFV is not found in infants with a severe HIE/poor prognosis during the first months after asphyxia (Figure 1). After the extremely high cerebral BFV during the first days of life significantly lower mean cerebral BFV develops during the first months after asphyxia in severe HIE infants. At the same age the enlargement of lateral ventricles, multicystic encephalopathy and the suboptimal head circumference develops in infants with a severe HIE / poor neurodevelopmental outcome suggesting decreased brain volume due to a massive loss of the brain tissue in infants with a severe HIE/ poor prognosis by this time (Ilves et al., 2009a).

It is not known whether this decrease in the mean BFV in infants with a severe HIE/poor prognosis is caused only by the low brain volume or whether these infants have lower metabolism or because of both problems. Severe HIE infants had a low head circumference with wide liquor spaces and hence the low brain volume and therefore the required cerebral $\mathrm{BFV}$ to fulfil energy requirements for the damaged decreased cerebral parenchyma can be lower. Such decreased brain volume probably no longer needs a normal blood flow. It is also possible that the requirement for energetic fuel is low because of the low metabolism in 
the damaged cells in the cases of severe brain damage. The only published case report, following longitudinal changes in cerebral metabolism in an infant with HIE and subsequent cerebral palsy, has demonstrated transient hypermetabolism in the neonatal period followed by severe hypometabolism later during childhood (Batista et al., 2007). More longitudinal data about cerebral blood flow and metabolism is needed to understand the causes of long term low cerebral blood flow velocities in infants with a severe HIE/poor prognosis months after birth asphyxia.

\subsection{US and Doppler findings in visceral organs}

Although the central nervous system is disturbed in $70 \%$ of infants after severe birth asphyxia (Martin-Ancel et al., 1995), up to $80-90 \%$ of infants develop disturbances in other organs (Martin-Ancel et al., 1995; Shah et al., 2004; Wayenberg et al., 1998). The interruption of the placental blood flow during labour and the decompensation of the circulatory responses lead to systemic hypotension and ischemia in different organs. Redistribution of the blood during asphyxia is the major protective mechanism in order to maintain the perfusion of vital organs such as the brain, heart and adrenal glands, but it causes ischemic damage to the visceral organs like kidneys and gut (Perlman, 2006; Stola \& Perlman, 2008). Early BFV changes have been documented in critically ill infants following birth asphyxia in the cerebral (Bennhagen et al., 1998; Ilves, et al., 2009b), renal (RA) (Ilves et al., 2009b; Luciano et al., 1998), superior mesenteric arteries (SMA) (Ilves et al., 2009b; Koc et al., 1998) or in CA (Ilves et al., 2009b).

Different patterns of post-injury BFV changes exist in the visceral arteries compared to the cerebral arteries in asphyxiated infants with HIE. The mean BFV in the SMA and CA (but not in the RA) increased in the infants with mild-moderate HIE during the first $12 \mathrm{~h}$ after asphyxia (Ilves et al., 2009a, 2009b). The reperfusion of ischemic intestine and gastric mucosa is characterised by an initial hyperaemia with ensuing mucosal repair, as shown in animal models (Meleagros et al., 1994). The increase in BFV, seen in the SMA and CA but not in the RA during the first hours after asphyxia, can be the compensatory hyperaemia in the gastrointestinal tract, stomach and liver in the infants with mildmoderate HIE. Such differences in the compensatory capabilities in the RA, SMA and CA can explain the differences in the frequency of severe organ failure found in asphyxiated infants. Renal failure is found to develop more often in $40-57 \%$ of asphyxiated infants compared to a lower rate $(30 \%)$ of gastrointestinal complications in asphyxiated term infants; liver failure is a rare complication in the infants with severe HIE (Martin-Ancel et al., 1995; Perlman et al., 1989).

The lack of hyperaemia in the SMA and CA and a decrease in BFV in the RA already during the first hours after asphyxia in severe HIE infants, despite vasoactive treatment and normal BP shows decreased compensatory capabilities in the infants with severe HIE to the restore blood flow in the visceral arteries. Extremely low BFV in all the visceral arteries was found during the first day in infants with a very long resuscitation period and the fatal outcome. These infants had normal blood pressure but a very high BFV in the cerebral arteries and a very low BFV in the visceral arteries already during the first day of life with the development of severe HIE, severe renal, gastrointestinal and hepatic failure as well as cardiac failure. Animal models have indicated that reperfusion is the main mechanism of injury after intestinal or renal ischemia; however, the post-ischemic 
reperfusion injury is related primarily to the magnitude and time of the total ischemia (Rangan \& Bulkley, 1993).

In infants with severe HIE or poor outcome, a progressive decrease in the mean BFV was found in the RA and SMA, being the lowest during the second day of life (Akinbi et al., 1994; Ilves et al., 2009b; Luciano et al., 1998). A decrease in the renal blood flow during the first day of life carries a high risk of the development of acute renal failure (Akinbi et al., 1994; (Ilves et al., 2009b; Luciano et al., 1998). A number of animal studies have provided evidence that oxygen metabolites, different vasoconstrictive molecules and intravascular clotting may play a role in the microcirculation derangement in the delayed progressive postischemic reperfusion injury (Fellman \& Raivio, 1997; Perlman, 2006). In normal infants, vasodilation secondary to the copious production of endothelium-derived nitric oxide (NO) is favoured, but endothelial cell injury could shift this balance in favour of endothelin (ET)1-mediated vasoconstriction and would limit NO production, leading to intestinal ischemia and the tissue injury as from humans with NEC (Nankervis et al., 2008). A hypoxic/ischemic insult with the resulting activation of the coagulation cascade also plays a role in renal hypoperfusion (Andreoli, 2004).

During the first day of life, pressure-passive BFV in the RA and SMA but not in the CA has been described earlier in healthy infants in the presence of open ductus arteriosus (Ilves et al., 2008). This may reflect the relatively good autoregulation of the blood flow in the CA in healthy and asphyxiated newborn infants with vasoactive treatment having a good effect; however, extra factors can redistribute the blood flow, sparing the blood flow to the CA and decreasing the blood to the SMA and RA.

Our findings indicate that differences exist in postasphyxic changes in BFV in the cerebral and visceral organs in different severities of HIE. Increased BFV develops in the SMA and $\mathrm{CA}$ in the infants with mild to moderate HIE early postinjury. A severe increase in BFV in the cerebral arteries, but a decrease in the renal and superior mesenteric arteries develops by the second day of life in a severe HIE infant, indicating that a therapeutic window exists for visceral damage. As in healthy infants, a relatively spared blood flow in the CA is found in asphyxiated newborn infants. No data exists how the BFV in visceral organs change during postasphyxial hypothermia.

\section{Outcome}

Outcomes of babies with HIE vary according to the severity of the injury. The children with mild HIE can be expected to recover and the children with the severe form either develop severe disability or die. Between $15 \%$ and $20 \%$ of infants suffering HIE die during the neonatal period, and an additional 25\% develop permanent neurologic deficits (Vannucci \& Perlman, 1997). The infants who survive a severe hypoxic insult with severe HIE typically go on to develop quadriparesis, choreoathetosis, severe seizure disorders, or mental retardation. The patients with moderate injuries invariably can develop spastic diplegia or quadriplegia (often falling under the umbrella term cerebral palsy) (Barkovich, 2005).

The children with moderate encephalopathy have a less certain prognosis (Ilves et al., 2009a), however the majority of infants with moderate HIE have major and/or cognitive disability in a long-term follow-up if followed during adolescence (Lindström et al., 2008) 


\section{Conclusions}

Sonography is an excellent tool in screening of asphyxiated infants with HIE and evaluating the prognosis of asphyxiated infants. Advances in the US equipment now permit the visualization of structures not previously shown. Despite some limitations, the US technique effectively depicts parenchymal abnormalities of the neonatal brain, showing good correlation with MRI findings. The parenchymal abnormalities depicted on US are not as florid or clearly visualized as on MRI and US might not depict as many focal lesions as MRI, especially those placed cortically. Therefore, US might severely underestimate the degree of injury, and the findings might indeed represent the tip of the iceberg. Despite this, US is a more effective modality in this group of patients than it has been suggested in the literature and remains an excellent screening modality for use in neonates too critically ill to be transported to MRI. MRI should ideally evaluate every infant with neonatal encephalopathy as early as possible, as the window required to demonstrate injury in DWI is small. However, high-quality US is very sensitive in detecting injuries and is often the only study available during the initial evaluation of these critcally ill patients or in those under hypothermic treatment. US provides an option for the interval follow-up assessment of these infants, even if the follow-up MRI is planned (Epelman et al., 2010). Differences exist in the blood flow velocity in the brain and in visceral organs in the infants with a different severity of HIE with a high cerebral blood flow and a low RI developing in the infants with a poor prognosis. In the infants with HIE treated with therapeutic hypothermia, the low resistance index is probably not as good a predictor of a poor outcome as in normothermia and further studies are needed in this area.

\section{References}

Adriani, G., Persico, A., Tursini, S., Ballone, E., D Cirotti \& Chiesa, PL. The renal-resistive index from the last 3 months of pregnancy to 6 months old. BJU International 2001; 87: 562.

Agata, Y., Hiraishi, S., Misawa, H., Hirota, H., Nowatari, M., Hiura, K., Fujino, M., Oguchi, K. \& Horiguchi, Y. Regional blood flow distribution and left ventricular output during early neonatal life: A quantitative ultrasonographic assessment. Pediatr Res 1994; 36: 805-810.

Akinbi, H., Abbasi, S., Hilpert, PL. \& Bhutni, VK. Gastrointestinal and renal blood flow velocity profile in neonates with birth asphyxia. J Pediatr 1994; 125: 625-627.

Andreoli, SP. Acute renal failure in the newborn. Semin Perinatol 2004; 28: 112-123.

Archer, LN., Levene, MI. \& Evans, DH. Cerebral artery Doppler ultrasonography for prediction of outcome after perinatal asphyxia. Lancet 1986; 2: 1116-1118.

Ashwal, S., Majcher, JS., Vain, N., \& Longo, LD. Patterns of fetal lamb regional cerebral blood flow during and after prolonged hypoxia. Pediatr Res 1980;14: 1104-1110.

Babcock, DS. \& Ball, W. Jr. Postasphyxial encephalopathy in full-term infants: US diagnosis. Radiology 1983; 148: 417-423.

Barkovich, AJ. 2005. Brain and spine injuries in infancy and childhood. In: Barkovich AJ, ed. Pediatric neuroimaging: 190-290, 4th ed, Lippincott Williams \& Wilkins, ISBN 978-14160-4918-0, Philadelphia. 
Barkovich, AJ. MR and CT evaluation of profound neonatal and infantile asphyxia. Am J Neuroradiol 1992; 13: 959-972.

Batista, CE., Chugani, HT., Juhasz, C., Behen, ME. \& Shankaran, S. Transient hypermetabolism of the basal ganglia following perinatal hypoxia. Pediatr Neurol 2007; 36: 330-333.

Bennhagen, RG., Weintraub, RG., Lundström, NR. \& Svenningsen, NW. Hypoxic-ischaemic encephalopathy is associated with regional changes in cerebral bblood flow velocity and alterations in cardiovascular function. Biol Neonate 1998;75:275286.

Biagas, K. Hypoxic-ischemic brain injury: advancements in understanding of mechanisms and potential avenues for therapy. Curr Opin Pediatr 1999; 11: 223-228.

Black, RE., Cousens, S., Johnson, HL., Lawn, JE., Rudan, I., Bassani, DG., Jha, P. et al. Global, regional, and national causes of child mortality in 2008: a systematic analysis. Lancet 2010; 375: 1969-1987 .

Blennow, M., Ingvar, M., Lagercranz, H., Stone-Elander, S., Eriksson, L., Forssberg, H., Ericson, K. \& Flodmark, O. Early 18FFDG positron emissionn tomography in infants with hypoxic/ischemic encephalopathy shows hypermetabolism during the psotasphyctic period. Acta Paediatr 1995; 84: 1289-95.

Bonfoco, E., Kraine, D., Ankarcroma, M., Nicotera, P. \& Lipton, SA. Apoptosis and necrosis: two distinct events, induced respectively by mild and intense insults with $\mathrm{N}$ methyl-Daspartate or nitri oxide/superoxide in cortical cell cultures. Proc Natl Acad Sci 1995; 92: 7162-7166.

Chugani, HT. \& Phelps, ME. Maturational changes in cerebral function in infants determined by 18FDG positron emission tomography. Science 1986; 231: 840-843.

Connolly, B., Kelehan, P., O’Brien, N., Gorman, W., Murphy, JF., King, M. \& Donoghue, V. The echogenic thalamus in hypoxic ischaemic encephalopathy. Pediatr Radiol 1994; 24: 268-271.

Coombs, RC., Morgan, ME., Durbin, GM., Booth, IW. \& McNeish, AS. Doppler assessment of human neonatal gut blood flow velocities: postnatal adaptation and response to feeds. J Pediatr Gastroenterol Nutr 1992; 15: 6-12.

Cordes, I., Roland, EH., Lupton, BA. \& Hill, A. Early prediction of the development of microcephaly after hypoxic-ischemic encephalopathy in the full-term newborn. Pediatrics 1994; 93: 703-707.

Deeg K-H Zerebrale Dopplersonographie im Kindersalter. Springer Verlag Berlin Heidelberg 1989

de Lange, C., Braband, K., Emblem, KE., Bjornerud, A., Løberg, EM., Saugstad, OD. \& Munkeby, BH. Cerebral Perfusion in Perinatal Hypoxia and Resuscitation Assessed by Transcranial Contrast-Enhanced Ultrasound and 3 T MRI in Newborn Pigs. Invest Radiol 2011; Jul 1.

Edwards, AD. \& Mehmet, H. Apoptosis in perinatal Hypoxic-ischaemic cerebral damage. Neuropathol Appl Neurobiol 1996; 22: 494-498. 
Edwards, AD., Yue, X., Cox, P., Hope, PL., Azzopardi, DV., Squier, MV. \& Mehmet, H. Apoptosis in the brains of infants suffering intrauterine cerebral injury. Pediatr Res 1997; 42: 684-689.

Edwards, AD., Brocklehurst, P., Gunn, AJ., Halliday, H., Juszczak, E., Levene, M., Strohm, B. et al. Neurological outcomes at 18 months of age after moderate hypothermia for perinatal hypoxic-ischaemic encephalopathy: synthesis and meta-analysis of trial data. BMJ 2010; 340: c363.

Ehehalt, S., Kehrer, M., Goelz, R., Poets, C. \& Schöning, M. Cerebral blood flow volume measurements with ultrasound: Intraobserver reproducibility in preterm and term neonates. Ultrasound Med Biol 2005; 31: 191-196.

Eken, P., Toet, MC. Groenendaal, F. \& de Vries, LS. Predictive value of early neuroimaging, pulsed Doppler and neurophysiology in full term infants with hypoxic-ischaemic encephalopathy." Arch Dis Child 1995; 73: F75-80.

Ellis, M., Manandhar, DS., Wyatt, J., Bolam, AJ. \& Costello, AM. Stillbirths and neonatal encephalopathy in Kathmandu, Nepal: an estimate of the contribution of birth asphyxia to perinatal mortality in a low-income urban population. Paediatr Perinat Epidemiol 2000; 14: 39-52.

Elstad, M., Whitelaw, A. \& Thoresen, M. Cerebral resistance index is less predictive in hypothermic encephalopathic newborns. Acta Paediatr 2011; 21.

Epelman, M., Daneman, A., Kellenberger, CJ., Aziz, A., Konen, O., Moineddin, R., White, H. \& Blaser, S. Neonatal encephalopathy: a prospective comparison of head US and MRI. Pediatr Radiol 2010; 40: 1640-1650.

Evans, DH., Levene, MI., Shortland, DB. \& Archer, LNJ. Resistance index, blood flow velocity, and resistance-area product in the cerebral arteries of very low birth weight infants during the the first week of life. Ultrasound in Med E Bio 1988; 14: 103-110.

Fellman, V., \& Raivio, KO. Reperfusion injury as the mechanism of brain damage after perinatal asphyxia. Pediatr Res 1997; 41: 599-606.

Ferrarri, F., Kelsall, AW., Rennie, JM. \& Evans, DH. The relationship between cerebral blood flow velocity fluctuations and sleep state in normal newborns. Pediatr Res 1994; 35: 50-54.

Ferriero, DM. Neonatal brain injury. N Engl J Med 2004; 351: 1985-1995.

Finer, NN., Robertson, CM., Richards, RT., Pinnell, LE. \& KL Peters. Hypoxic-ichemic encephalopathy in term neonates: perinatal factors and outcome. J Pediatr 1992; 98: 112-117.

Frewen, TC., Kissoon, N., Kronick, J. Fox, M., Lee, R., Bradwin, N. \& Chance, G. Cerebral blood flow, cross-brain oxygen extraction, and fontanelle pressure after hypoxicisćhemic injury in newborn infants. J Pediatr 1991; 118, 265-271.

Fukuda, S., Mizuno, K., Kawai, S., Kakita, H., Goto, T., Hussein, MH., Daoud, GA. et al. Reduction in cerebral blood flow volume in infants complicated with hypoxicischemic encephalopathy resulting in cerebral palsy. Brain Dev 2008; 30: 246-253.

Hagmann, CF., Brotschi, B., Bernet, V., Latal, B., Berger, TM. \& Robertson, NJ. Hypothermia for perinatal asphyxial encephalopathy. Swiss Med Wkly 2011; 16, nr 141:w13145. doi: 10.4414/smw.2011.13145. 
Hayashi, T., Ichiyama, T., Uchida, M., Tashiro, N. \& Tanaka, H. Evaluation by colour Doppler and pulsed Doppler sonography of blood flow velocities in intracranial arteries during the early neonatal period. Eur J Pediatr 1992; 151: 461-465.

Hertzberg, BS., Pasto, ME., Needleman, L., Kurtz, AB. \& Rifkin, MD. Postasphyxial encephalopathy in term infants: sonographic demonstration of increased echogenicity of the thalamus and basal ganglia. J Ultrasound Med 1987; 6: 197202.

Hoehn, T., Hansmann, G., Bührer, C., Simbruner, G., Gunn, AJ., Yager, J., Levene, M., et al. Therapeutic hypothermia in neonates. Review of current clinical data, ILCOR recommendations and suggestions for implementation in neonatal intensive care units. Resuscitation 2008; 78: 7-12.

Huang, BY. \& Castillo, M. Hypoxic-ischemic brain injury: imaging findings from birth to adulthood. Radiographics 2008; 28: 417-439.

Ilves, P., Lintrop, M., Talvik, I., Muug, K., Maipuu, L. \& Metsvaht, T. Low cerebral blood flow velocity and head circumference in infants with severe hypoxic ischemic encephalopathy and poor outcome. Acta Paediatr 2009; 98: 459-465.

Ilves, P., Lintrop, M., Talvik, I., Muug, K. \& Maipuu, L. Changes in cerebral and visceral blood flow velocities in asphyxiated term infants with hypoxic ischemic encephalopathy. J Ultrasound Med 2009; 28: 1471-1480.

Ilves, P., Lintrop, M., Talvik, I., Muug, K., Asser, K. \& Veinla, M. Developemntal changes in cerebral and visceral blood flow velocity in healthy neonates and infants. $J$ Ultrasound Med 2008; 27: 199-207.

Ilves, P., Lintrop, M., Metsvaht, T., Vaher, U. \& Talvik, T. Cerebral blood flow velocities in predicting outcome of asphyxiated newborn infants. Acta Paediatr 2004; 93: 523528.

Johnston, MV., Trescher, WH., Ishida, A. \& Nakajima, W. Neurobiology of hypoxic-ischemic injury in the developing brain. Pediatr Res 2001; 49: 735-741.

Kangström, E., Smith, M-L. \& Siesjö, BK. Local cerebral blood flow in the recovery period following incomplete cerebral ischemia in the rat. J Cerebr Blood Flow Metab 1983; 3: 170-182.

Kelner, M., Krägeloh-Mann, I., Goelz, R. \& Schöning, M. The development of cerebral perfusion in healthy preterm and term newborns. Neuropediatrics 2003; 34: 281286.

Kempley, ST., Vyas, S., Bower, S., Nicolaides, KH. \& Gamsu, H. Cerebral and renal artery blood flow velocity before and after birth. Early Human Dev 1996; 46: 165-174.

Kinnala, A., Suhonen-Polvi, H., Äärimaa, H., Kero, T., Korvenranta, H., Ruotsalainen, U., et al. Cerebral metabolic rate for glucose during the first six months of life: an FDG positron emission tomography study. Arch Dis Child 1996; 74: F153-157.

Koc, E., Arsan, S., Ozcan, H., Zenciroglu, A., Erdem, I. \& Ertogan, F. The effect of asphyxia on gut blood flow in term neonates. Indian J Pediatr 1998; 65: 297-302.

Koehler, RC., Traystman, RJ. \& Jones, J. Regional blood flow and O2 transport during hypoxic and CO hypoxia in neonatal and adult sheep. Am J Physiol 1985; 248: H 118-124. 
Kojo, M., Ogawa, T. \& Yamada, K. Normal developmental changes in carotid arterial blood flow measured by Doppler flowmetry in children. Pediatr Neurol 1996; 14: 313-316.

Levene, MI., Fenton, AC., Evans, DH., Archer, LNJ., Shortland, DB. \& Gibson, NA. Severe birth asphyxia and abnormal cerebral blood flow velocty. Dev Med Child Neurol 1989; 31: 427-434.

Liao, MF., Chaou, WT., Tsao LY., Nishida, H. \& Sakanoue, M. Ultrasound measurement of the ventricular size in newborn infants. Brain Dev 1986; 8: 262-268.

Lindström, K., Hallberg, B., Blennow, M., Wolff, K., Fernell, E. \& Westgren, M. Moderate neonatal encepehalopathy: pre- and perinatal risk factors and long-term outcome. Acta Obstet Gynecol Scand 2008; 87: 503-509.

Lipman, B., Serwer, GA. \& Brazy, JE. Abnormal cerebral hemodynamics in preterm infants with patent ductus arteriosus. Pediatrics 1982; 69: 778-781.

Lorek, A., Takei, Y., Cady, E., Wyatt, J., Penrice, J., Edwards, A., et al. Delayed ("secondary") cerebral energy failure after acute hypoxia -ischemia in the newborn piglet: continous 48-hour studeis by phosphorus magnetic resonance spectroscopy. Pediatr Res 1994; 36: 699-706.

Lowe, LH., \& Bailey, Z. Sate-of-the-art cranial sonongraphy: Part I, modern techniques and image interpretation. AJR Am J Roentgenol 2011; 196: 1028-1033.

Lowe, LH.,\& Bailey, Z. State-of-art cranial sonongraphy: Part 2, pitfalls and variants. Am J Roentgenol 2011; 196:1034-1039.

Luciano, R., Gallini, F., Romagnoli, C., Papacci, P. \& Tortorolo, G. Doppler evaluation of renal blood flow velocity as a predictive index of acute renal failure in perinatal asphyxia. Eur J Pediatr 1998; 157: 656-660.

Marlow, N. \& Budge, H. Prevalence, causes, and outcome at 2 years of age of newborn encephalopathy. Arch Dis Child Fetal Neonatal Ed 2005; 90: F 193-194.

Martin, E., \& Barkovich, AJ. Magnetic resonance imaging in perinatal asphyxia. Arch Dis Child 1995; 72: F 62-70.

Martin-Ancel, A., Garcia-Alix, A., Gayá, F., Carbañas, F., Burgueros, M. \& Quero, J. Multiple organ involvement in perinatal asphyxia. J Pediatr 1995; 127: 786-793.

Martinussen, M., Brubakk, AM., Linker, DT., Vik, T. \& Yao, AC. Mesenteric blood flow velocity and it relation to circulatory adaptation during the first week of life in healthy term infants. Pediatr Res 1994; 36: 334-339.

Meek, JH., Elwell, CE., McCormick, DC., Edwards, AD., Townsend, JP., Stewart, A., et al. Abnormal cerebral haemodynamics in perinatally asphyxiated neonates related to outcome. Arch Dis Child Fetal Neonatal Ed 1999; 81: F 110-115.

Meleagros, L., Ghatei, MA. \& Bloom, SR. Release of vasodilator, but not vasoconstrictor, neuropeptides and of enteroglucagon by intestinal ischaemia/reperfusion in the rat. Gut 1994; 35: 1701-1706.

Mercuri, E., Ricci, D., Cowan, FM., Lessing, D., Frisone, MF., Haataja, L., Counsell, SJ., et al. Head growth in infans with hypoxic-ischemic encephalopathy: correlation with neonatal magnetic resonance imaging. Pediatrics 2000; 106: 235-243.

Nankervis, CA., Giannone, PJ. \& Reber, KM. The neonatal intestinal vasculature: contributing factors to necrotizing enterocolitis. Semin Perinatol 2008; 32: 83-91. 
Nelson, KB. \& Leviton, A. How much of neonatal encephalopathy is due to birth asphyxia? Am J Dis Child 1991; 145: 1325-1331.

North, K., \& Lowe, L. Modern head ultrasound: normal anatomy, variants, and pitfalls that may simulate disease. Ultrasound Clin 2009; 4: 497-512.

Perlman, JM., Wyllie, J., Kattwinkel, Atkins, DL., Chameides, L., Goldsmith, JP., Guinsburg, R., et al. Neonatal resuscitation: 2010 International Consensus on Cardiopulmonary Resuscitation and Emergency Cardiovascular Care Science with Treatment Recommendations. Circulation 2010; 122: S 516-538.

Perlman, JM. Summary proceedings from the neurology group on hypoxic-ishemic encephalopathy. Pediatrics 2006; 117: S 28-33.

Perlman, JM., Tack, ED., Martin, T., Shackelford, G. \& Anon, E. Acute systemic organ injury in term infants after asphyxia. Am J Dis Child 1989; 143: 617-620.

Persico, A., Tursini, S., Ballone, E., Cirotti, D. \& Chiesa, PL. The renal-resistive index from the last 3 months of pregnancy to 6 months old. BJU International 2001; 87: 562.

Pierrat, V., Haouari, N., Liska, A., Thomas, D., Subtil, D. \& Truffert, P. Prevalence, causes, and outcome at 2 years of age of newborn encephalopathy: population based study. Arch Dis Child Fetal Neonatal Ed 2005; 90: F 257-261.

Pryds, O. Control of cerebral circulation in the high-risk neonate. Ann Neurol 1991; 30: 321329.

Pryds, O., Greisen, G., Lou, H. \& Friis-Hansen, B. Vasoparalysis accociated with brain damage in asphyxiated term infants. J Pediatr 1990; 117: 119-25.

Rangan, U. \& Bulkley, GB. Prospects for treatment of free radical-mediated tissue injury. $\mathrm{Br}$ Med Bull 1993; 49: 700-718.

Robertson, NJ. \& Edwards, AD. Recent advances in developing neuroprotective strategies for perinatal asphyxia. Current Opinion in Pediatrics 1998; 10: 575-580.

Rosenberg, AA. Cerebral blood flow and O2 metabolism after asphyxia in neonatal lambs. Pediatr Res 1986; 20: 778-782.

Roth, SC., Baudin, J., Cady, E., Johal, K., Townsend, JP., Wyatt, JS., Reynolds, EO. \& Stewart, AL. Relation of deranged neonatal cerebral oxidative metabolism with neurodevelopmental outcome and head circumference at 4 years. Dev Med Child Neurol 1997; 39: 718-725.

Rutherford, M., Pennock, J., Schwieso, J., Cowan, F. \& Dubowitz, L. Hypoxic-ischaemic encephalopathy: early and late magnetic resonance imaging findings in relation to outcome. Arch Dis Child 1996; 75: F145-151.

Rutherford, MA., Pennock, JM., Schwieso, JE., Cowan, FM. \& Dubowitz, LM. Hypoxicischemic encephalopathy: early magnetic resonance imaging findings and their evolution. Neuropediatrics 1995; 26: 183-191.

Rutherford, MA., Pennock, JM. \& Dubowitz, LM. Cranial ultrasound and magnetic resonance imaging in imaging in hypoxic-ischaemic encephalopoathy: a comparison with outcome. Dev Med Child Neurol 1994; 36: 813-825.

Sarnat, HB. \& Sarnat, MS. Neonatal encephalopathy following fetal distress. Arch Neurol 1976; 33: 698-705. 
Shadid, M., Moison, R., Steendijik, P., Hiltermann, L., Berger, HM. J\& van Bel, F. The effect of antioxidative combination therapy on post hypoxic-ischemic perfusion metabolism and electrical activity of the newbron brain. Pediatr Res 1998; 44: 11924.

Shah, P., Riphagen, S., Beyene, J.\& Perlman, M. Multiorgan dysfunction in infants with post-asphyxial hypoxic-ischaemic encephalopathy. Arch Dis Child 2004; 89: F 152155.

Shalak, L. \& Perlman, JM. Hypoxic-ischemic brain injury in the term infant: current concepts. Early Hum Dev 2004; 80: 125-141.

Stark, JE. \& Seibert, JJ. Cerebral artery Doppler ultrasonography for prediction of outcome after perinatal asphyxia. J Ultrasound Med 1994; 13: 595-600.

Stola, A. \& Perlman, J. Post-resuscitation strategies to avoid ongoing injury following intrapartum hypoxia-ischemia. Semin Fetal Neonatal Med 2008; 13: 424-431.

Takahashi, T., Shirane, R. Sato, S. \& Yoshimoto, T. Developmental changes of cerebral blood flow and oxygen metabolism in children. AM J Neuroradiol 1999; 20: 917-922.

Thoresen, M. \& Whitelaw, A. Cardiovascular changes during mild therapeutic hypothermia and rewarming in infants with hypoxic-ischemic encephalopathy. Pediatrics 2000; 106: 92-99.

Thorngren-Jerneck, K., Ohlsson, T., Sandell, A., Erlandsson, K., Strand, SE., Ryding, E., Svenningsen, NW. Cerebral glucose metabolism measured by positron emission tomography in term infants with hypoxic-ischemic encephalopathy. Pediatr Res 2001; 49: 495-501.

van Bel, F., Shadid, M., Moison, RM., Dorrepaal, CA., Fontijn, J., Monteiro, L., et al. Effect of allopurinol on postasphyxial free radical formation, cerebral hemodynamics, and electrical brain activity. Pediatrics 1998; 101: 185-193.

van Wezel Meijler, G., Steggerda, SJ. \& Leijser, LM. Cranial ultrasonongraphy in neonates: role and limitations. Semin Perinatol 2010; 34: 28-38.

Vannucci, RC. \& Perlman, JM. Interventions for perinatal hypoxic-ischemic encephalopathy. Pediatrics 1997; 100: 1004-1014.

Volpe JJ. Neurology of the newborn. WB Saunders Company. $5^{\text {th }}$ ed 2008.

Wayenberg, JL., Vermeylen, D. \& Damis, E. Definition of asphyxia neonatorum and incidence of neurologic and systemic complications in full-term newborn. Arch Pediatr 1998; 5: 1065-1071.

Weir, FJ., Fong, K., Ryan, ML., Myhr, T. \& Ohlsson, A. Superior mesenteric artery and renal artery blood flow velocity measurements in neonates: technique and interobserver reliability. Pediatr Radiol 1995; 25; 145-148.

Weissner, C., Vogel, P., Neumann-Haefelin, T. \& Hossmann, K-A. Molecular correlates of delayed neuronal death following transient forebarin ischemia in the rat. Acta Neurochir 1996; 66: 1-7.

Wyatt, JS., Edwards, AD., Azzopardi, D. \& Reynolds, EO. Magnetic resonance and near infrared spectroscopy for investigation of perinatal hypoxic-ishaemic brain injury. Arch Dis Child 1989; 64: 953-963.

Yildirim, H., Gungor, S., Cihangiroglu, MM. \& Aygun, AD. Doppler studies in normal kidney of preterm and term neonates: changes in relation to gestational age and birth weight. J Ultrasound Med 2005; 24: 623-627. 
Yoxall, CW. \& Weindling, AM. Measurement of cerebral oxygen consumption in the human neonate using near infrared spectroscopy: cerebral oxygen consumption increases with advancing gestational age. Pediatr Res 1998; 44: 283-290. 


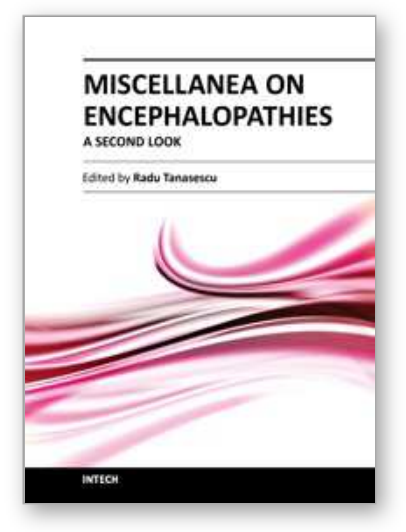

\author{
Miscellanea on Encephalopathies - A Second Look \\ Edited by Dr. Radu Tanasescu
}

ISBN 978-953-51-0558-9

Hard cover, 390 pages

Publisher InTech

Published online 25, April, 2012

Published in print edition April, 2012

The book project "Miscellanea on Encephalopathies-a second look" aims to cover some of the important aspects regarding metabolic, hypoxic, neoplasm- and drug-related encephalopathies, by transmitting valuable information filtered through the real life clinical and research experience of the authors.

\title{
How to reference
}

In order to correctly reference this scholarly work, feel free to copy and paste the following:

Pilvi llves (2012). Sonographic Changes in Hypoxic-Ischaemic Encephalopathy, Miscellanea on Encephalopathies - A Second Look, Dr. Radu Tanasescu (Ed.), ISBN: 978-953-51-0558-9, InTech, Available from: http://www.intechopen.com/books/miscellanea-on-encephalopathies-a-second-look/sonographicchanges-in-hypoxic-ischaemic-encephalopathy

\section{INTECH}

open science | open minds

\section{InTech Europe}

University Campus STeP Ri

Slavka Krautzeka 83/A

51000 Rijeka, Croatia

Phone: +385 (51) 770447

Fax: +385 (51) 686166

www.intechopen.com

\section{InTech China}

Unit 405, Office Block, Hotel Equatorial Shanghai

No.65, Yan An Road (West), Shanghai, 200040, China

中国上海市延安西路65号上海国际贵都大饭店办公楼405单元

Phone: +86-21-62489820

Fax: +86-21-62489821 
(C) 2012 The Author(s). Licensee IntechOpen. This is an open access article distributed under the terms of the Creative Commons Attribution 3.0 License, which permits unrestricted use, distribution, and reproduction in any medium, provided the original work is properly cited. 